\title{
Genomic pattern analysis of Burkholderia mallei field isolates by pulsed-field gel electrophoresis (PFGE) discriminatory typing
}

\author{
Shojaat Dashtipour ${ }^{1}$, Keyvan Tadayon ${ }^{2}$, Sajjad Yazdansetad ${ }^{3}$, Nader Mosavari ${ }^{1 *}$, Rouhollah Keshavarz ${ }^{1}$ \\ ${ }^{I}$ Department of Tuberculin and Mallein, Razi Vaccine and Serum Research Institute, Agricultural Research, \\ Education and Extension Organization (AREEO), Karaj, Iran \\ ${ }^{2}$ Department of Veterinary Aerobic Bacteria Vaccines, Razi Vaccine and Serum Research Institute, Agricultural \\ Research, Education and Extension Organization (AREEO), Karaj, Iran \\ ${ }^{3}$ Laboratory Sciences Research Center, Golestan University of Medical Sciences, Gorgan, Iran
}

Received: May 2021, Accepted: June 2021

\begin{abstract}
Background and Objectives: Glanders is a serious zoonotic disease caused by Burkholderia mallei. Prevention, control, and treatment strategies of glanders are prerequisites for microbial source tracking. The present study was aimed to analyze the genomic pattern of B. mallei Iranian field isolates by pulsed-field gel electrophoresis (PFGE) typing.

Materials and Methods: B. mallei isolates were aerobically cultured in nutrient broth/agar supplemented with glycerol $4 \%$ for $48 \mathrm{~h}$ at $37^{\circ} \mathrm{C}$. API $20 \mathrm{NE}$ identification system was used for the biochemical characterization. Genomic DNA of bacterial isolates was extracted using OIE-recommended protocol. Molecular identification of bacterial isolates was done based on amplification of BimA and IS407-flip genes. PFGE was applied to prepare the genomic pattern of $B$. mallei isolates. The guinea pig was used as a suitable model for studying the histopathological characterization of $B$. mallei.

Results: In both enzymatic digestion patterns by using AflII and VspI, we found three different clonal types; I) PFGE type of B. mallei Razi 325 strain, II) PFGE type of Tiger, Kordan, and Oshnavieh strains, and III) PFGE type of Semirom strain. B. mallei Razi 325 was categorized as unrelated strain which was belonged to the different cluster differing more than four bands.

Conclusion: PFGE showed more discriminatory power and considerable reproducibility for molecular typing of $B$. mallei strains in our study. It is standardized the approaches for outbreak detection, pathogen phylogeny, molecular epidemiology, and population studies.
\end{abstract}

Keywords: Burkholderia mallei; Pulsed-field gel electrophoresis; Glanders; Zoonoses; Biological warfare

\section{INTRODUCTION}

Burkholderia mallei, a Gram-negative and facultative intracellular coccobacillus is the causative agent of glanders, a serious pulmonary disease of solipeds (i.e., horses, mules, and donkeys) endemic to
Asia, the Middle East, Africa, and Central and South America (1). Equine is the preferred host for glanders and it is largely due to ingestion of feed or water contaminated with nasal discharges from infected animals. Moreover, the infection has been reported in other animals following the consumption of glander-

*Corresponding author: Nader Mosavari, Ph.D, Department of Tuberculin and Mallein, Razi Vaccine and Serum Research Institute, Agricultural Research, Education and Extension Organization (AREEO), Karaj, Iran. Tel: +98-9122611438 Fax: +98-2634552194 Email: nmosavari@gmail.com 
ous horses (2). The manifestation of glanders is usually chronic in the horse, while in mule, zebra, and donkey the disease is acute (3). Glanders is known as a zoonotic disease predominantly affecting Equidae and infrequently human beings through the occupational exposure and biological warfare (BW) (4). B. mallei, a known biothreat agent, has been listed as the Category B Potential Bioterrorism agent by the Centers for Disease Control and Prevention (CDC) (5).

Iran is on the unintended path of regional glanders due to the existence of geographical and economical commonalities with the neighboring countries possessing endemic diseases and consequently, they have been strengthening the source tracking on $B$. mallei Iranian strains. Furthermore, the weakness of neighboring countries in controlling and preventing the diseases and the passage of the pack animals, beast of burden, at the country's borders have made Iran the major center of glanders in the world (6).

Recently, sporadic reports of the glanders in the western provinces of Iran, loss of a male Siberian (or Amur) tiger, as well as the two lions from the Tehran Zoological Garden due to the consumption of contaminated donkey's meat with $B$. mallei are alarming for the occurrence and rising prevalence of disease in Iran (7).

Next-generation sequencing (NGS) technology has enabled noteworthy advances in molecular typing and epidemiological studies of microorganisms. However, many laboratories not equipped with sequencing tools. Pulsed-field gel electrophoresis (PFGE) is one of the current laboratories 'gold standards' and a powerful DNA-based molecular typing technique applied to distinguish and differentiate genetic relationships in pathogenic isolates of $B$. mallei (7). The prevention, control, and treatment strategies of the glanders are prerequisites to identify and type the $B$. malle $i$ isolates circulating in the country and addressing in our study. The present study aimed to analyze the genomic pattern of $B$. mallei Iranian field isolates by pulsed-field gel electrophoresis (PFGE) discriminatory typing.

\section{MATERIALS AND METHODS}

Bacterial isolates, growth conditions and identification. The Razi Vaccine and Serum Research Institute (RVSRI)-archived isolates of Burkholderia mal- le $i$ were addressed in the study (Table 1). In addition to the four wild-type isolates, the standard strain of $B$. mallei Razi 325 (RTCC 2375) was also used. B. mallei Razi 325 is the non-native, smooth, and virulent laboratory strain that has been gifted to the RVSRI by Sweden. This strain has been used in the production of the purified protein derivative (PPD)-mallein in the RVSRI since 1956. The RVSRI-archived isolates of B. mallei are cultured in tryptic soy broth (TSB) containing $20 \%$ glycerol and kept as stock of freezedried $\left(-80^{\circ} \mathrm{C}\right)$ cultures for the next reviving.

B. mallei isolates from frozen stocks were aerobically cultured in $100 \mathrm{ml}$ nutrient broth supplemented with glycerol 4\%, polymyxin E (colistin) 1000 $\mathrm{U}$, bacitracin $250 \mathrm{U}$, cycloheximide (actidione) 0.25 $\mathrm{mg}$, and horse serum $10 \%$ for $48 \mathrm{~h}$ at $37^{\circ} \mathrm{C}$ to get optimal growth. API 20NE identification system (bioMérieux®, France) was used for the biochemical characterization of the bacterial isolates. B. mallei isolates were inoculated into sodium chloride solution $0.85 \%$, and turbidity was adjusted to $0.5 \mathrm{McFarland}$ standard. The inoculums were distributed into test cupules and incubated for $24 \mathrm{~h}$ at $37^{\circ} \mathrm{C}$. Biochemical reactions were read as positive/negative, translated into numerical profiles, and interpreted by APILAB Plus software, version 3.3.3. Further biochemical tests, including catalase, oxidase, Triple Sugar Iron (TSI), Sulfur Indole Motility (SIM), Oxidation-Fermentation (OF), gelatin liquefaction, and nitrate reduction were also carried out on B. mallei isolates. All the procedures were performed in a biosafety level 3 (BSL-3).

Inactivation of bacterial isolates. Prior to DNA preparation and PCR assay, the bacterial isolates were heat-inactivated from pure cultures according to the guidelines and precautions for the diagnosis of $B$. mallei infectious agent (8). The bacterial isolates were inactivated at $56^{\circ} \mathrm{C}$ for 1 hour in a water bath. The viability testing of isolates was checked on blood agar following the incubation at $37^{\circ} \mathrm{C}$ for $48 \mathrm{~h}$.

Genomic DNA extraction and PCR detection. Genomic DNA of bacterial isolates was extracted using an optimized protocol as described by the World Organization for Animal Health (OIE) (8). In brief, the bacterial colonies were inoculated to the lysis buffer (6 mM Tris-HCl, $1 \mathrm{M} \mathrm{NaCl,} 0.1 \mathrm{M}$ EDTA, 0.5\% SDS) containing $0.5 \%$ Tween 20 and $2 \mathrm{mg} / \mathrm{ml}$ Proteinase $\mathrm{K}$, and then heated at $65^{\circ} \mathrm{C}$ for $10 \mathrm{~min}$, fol- 
SHOJAAT DASHTIPOUR ET AL.

Table 1. The RVSRI-archived isolates of Burkholderia mallei used in this study

\begin{tabular}{lccc}
\hline Isolate & Host & Date of isolation & Location \\
\hline Tiger & Siberian/Amur tiger & 2010 & Eram Park Zoo, Tehran, Iran \\
Kordan & Mare & 2013 & Kordan, Alborz, Iran \\
Oshnavieh & Mule & 2014 & Oshnavieh, West Azerbaijan, Iran \\
Semirom & Mare & 2016 & Semirom, Isfahan, Iran \\
\hline
\end{tabular}

lowed by centrifugation at $16,000 \times \mathrm{g}$ for $10 \mathrm{~min}$. The supernatant was purified by a mixture of phenol-chloroform-isoamyl alcohol (25:24:1). Genomic DNA was precipitated using cold isopropanol, then washed with $70 \%$ ethanol, and finally dissolved in TE buffer. The quantification and qualification of DNA samples were assayed by NanoDrop ${ }^{\mathrm{TM}} 3300$ Fluorospectrometer (Thermo Scientific, USA).

Molecular identification of bacterial isolates was done based on amplification of BimA, IS407-flip, and 23S rRNA target genes (Table 2).

PCR amplifications were carried out using a Mastercycler PeQ STAR Gradient (PeQLab, Germany) in a total volume of $16 \mu \mathrm{l}$ mixture containing $8 \mu \mathrm{l}$ the ready-to-use $2 \times$ Taq DNA Polymerase Master Mix RED (Ampliqon, Denmark), $0.4 \mu$ l each of primers (5 pmol/ $\mu \mathrm{l}$ ), and $1.5 \mu \mathrm{l}$ DNA template $(\sim 25 \mathrm{ng})$. The PCR conditions began with an initial denaturation at $94^{\circ} \mathrm{C}$ for $5 \mathrm{~min}$, followed by 30 cycles of denaturation at $94^{\circ} \mathrm{C}$ for $30 \mathrm{~s}$, annealing at $56^{\circ} \mathrm{C}$ for $30 \mathrm{~s}$ (for $\mathrm{BimA}$ ) and annealing at $65^{\circ} \mathrm{C}$ for $30 \mathrm{~s}$ (for IS407-flip), and extension at $72^{\circ} \mathrm{C}$ for $60 \mathrm{~s}$. Then final extension was done at $72^{\circ} \mathrm{C}$ for $7 \mathrm{~min}$. The $5.0 \mu \mathrm{l}$ PCR product obtained was analyzed on $1.5 \%$ agarose gel in $0.5 \mathrm{x}$ TBE buffer stained with RedSafe ${ }^{\mathrm{TM}}$ Nucleic Acid Staining as a visualizing agent and run for $45 \mathrm{~min}$ at $90 \mathrm{~V}$.

Pulsed-field gel electrophoresis (PFGE). $B$. mallei isolates were grown in nutrient agar with $1 \%$ glycerol, then a loopful of bacterial culture was resuspended into cell suspension solution, CSB, (75 mM $\mathrm{NaCl}, 25 \mathrm{mM}$ EDTA, $\mathrm{pH}$ 8) and harvested at $\mathrm{OD}_{600}$ of 1.2 corresponding to a cell density of $\sim 10^{9}$ cells $/ \mathrm{ml}$. The suspension of bacteria was inactivated at $65^{\circ} \mathrm{C}$.

The CSB was mixed 1:1 with molten $2 \%$ low-melting point ultrapure agarose (Cleaver Scientific, UK) and pipetted into plug casts. The plugs were placed in cell-lysis buffer, CLB, (50 mM EDTA, $50 \mathrm{mM}$ Tris, $0.1 \%$ SDS, and $1 \% \mathrm{~N}$-lauryl sarcosine sodium (W/V), $500 \mu \mathrm{g} / \mathrm{ml}$ proteinase $\mathrm{K}, \mathrm{pH}$ 8) for 16 hours to eliminate the cell components. The plugs were washed three times with Tris-EDTA (TE 1x) buffer, $\mathrm{pH}$ 8.0, followed by incubation at $37^{\circ} \mathrm{C}$ for $15 \mathrm{~min}$. The plugs were cut into $1 \times 4 \times 4 \mathrm{~mm}$ fragments and digested by AflII and VspI (AseI) enzymes (Thermo Scientific, USA) at $37^{\circ} \mathrm{C}$ for 16 hours before being loaded onto a $1 \%$ agarose gel in $0.5 x$ TBE buffer ( $40 \mathrm{mM}$ Tris, 45 $\mathrm{mM}$ boric acid, $1 \mathrm{mM}$ EDTA, $\mathrm{pH}$ 8.3). The wells were overlaid with $1 \%$ low melting agarose. PFGE lambda ( $\lambda$ ) ladder, $48.5-1000 \mathrm{~kb}$ in $48.5 \mathrm{~kb}$ increments, concatemers of $\lambda$ cl857Sam7 lambda DNA was loaded as standard. The PFGE was run on a CHEF MAPPER system (Bio-Rad Laboratories, Hercules, CA, USA) for 18 hours at $6 \mathrm{~V} / \mathrm{cm}$, and $14^{\circ} \mathrm{C}$, at an included angle of $120^{\circ}$ using the following parameters: initial switch time, final switch time, and run time; block 1: 10-50 V for 7 hours, block 2: 30-40 V for 7 hours, and block 3: $50-90 \mathrm{~V}$ for 4 hours.

Staining the gel and PFGE pattern analysis. The gel was detached from the cell, transferred into a $0.5 \mu \mathrm{g} / \mathrm{ml}$ ethidium bromide solution in $\mathrm{dH}_{2} \mathrm{O}$, and stained for 20-30 minutes. The gel was destined in distilled water for 2 hours. DNAs were visualized by

Table 2. The specific primers for PCR amplification of B. mallei target genes

\begin{tabular}{llccr}
\hline Target & Primer sequence $\left(\mathbf{5}^{\prime} \rightarrow \mathbf{3}^{\prime}\right)$ & Amplicon size $(\mathbf{b p})$ & Annealing $\left({ }^{\circ} \mathbf{C}\right)$ & Reference \\
\hline BimA & F: TTCGATCGATTCCTGCTATC & 250 & 56 & $(9)$ \\
& R: GCGTTAAACGCCGTACTTTC & & & $(10)$ \\
IS407-flip & F: TCAGGTTTGTATGTGCTCGG & 989 & 65 & $(11)$ \\
& R: CTAGGTGAAGCTCTGCGCGAG & & 58 & \\
& F: AAACCGACACAGGTGG & 526 & & \\
\hline
\end{tabular}


placing the gel on a UV transilluminator (254-360 $\mathrm{nm})$. The pattern analysis and dendrogram construction were carried out with BioNumerics version 7.5 (Applied Maths NV, Sint-Martens-Latem, Belgium).

Histopathological analysis. The histopathological analysis of $B$. malle $i$ strains was studied in guinea pig as an animal model. A male guinea pig, with a weight of about $370 \mathrm{~g}$ and 9 weeks of age, was administered with a $10^{7} \mathrm{CFU} / \mathrm{ml}$ crude suspension of heat-inactivated $B$. mallei by $1 \mathrm{ml}$ of the inoculums in the left lower abdominal quadrant intraperitoneally (IP) using a 25-gauge needle. A control group (negative control) of the guinea pig was also injected with $1 \mathrm{ml}$ phosphate-buffered saline (0.01 M PBS, pH 7.2). The guinea pigs were kept in a separate clean cage of an isolator under aseptic conditions and monitored once daily for 72 hours. Bacterial colonization in the testicle and its swelling (also called Strauss phenomenon) was followed after 72 hours. The testicular tissue of the guinea pig was collected and fixed in $10 \%$ neutral-buffered formaldehyde, embedded in paraffin wax, processed routinely, and sectioned into $5 \mu \mathrm{m}$ thick slices. The tissue sections were then placed on a slide glass and stained with hematoxylin and eosin (H\&E) finally, they were examined by light microscopy at $\times 40$ magnification.

\section{RESULTS}

Bacterial culture, identification and biotyping characteristics. The small, smooth, and grey colonies of $B$. mallei strains were seen on nutrient agar after $48 \mathrm{~h}$ incubation at $37^{\circ} \mathrm{C}$ (Fig. 1). Catalase positive, oxidase negative, indole negative, $\mathrm{H}_{2} \mathrm{~S}$ negative, non-motile, no change on TSI, nitrate reduction positive, and growth ability at $37^{\circ} \mathrm{C}$ were also confirmed for $B$. mallei isolates. The other biochemical profile of isolates was positively found for $\mathrm{NO}_{3}$ (potassium nitrate), $\mathrm{ADH}$ (L-arginine), GLU (D-glucose), NAG (N-acetyl-glucosamine), GNT (potassium gluconate) by using API 20NE system (Fig. 2). Amplification of IS407-flip and BimA genes of B. mallei isolates showed the expected sizes of $989 \mathrm{bp}$ and $250 \mathrm{bp}$, respectively (Fig. 3). PCR amplification of 23 rRNA of B. mallei isolates also showed the amplicon size of 526 bp (Fig. 4).

DNA restriction patterns of $B$. mallei strains were successfully generated by PFGE (Fig. 5). The repro-

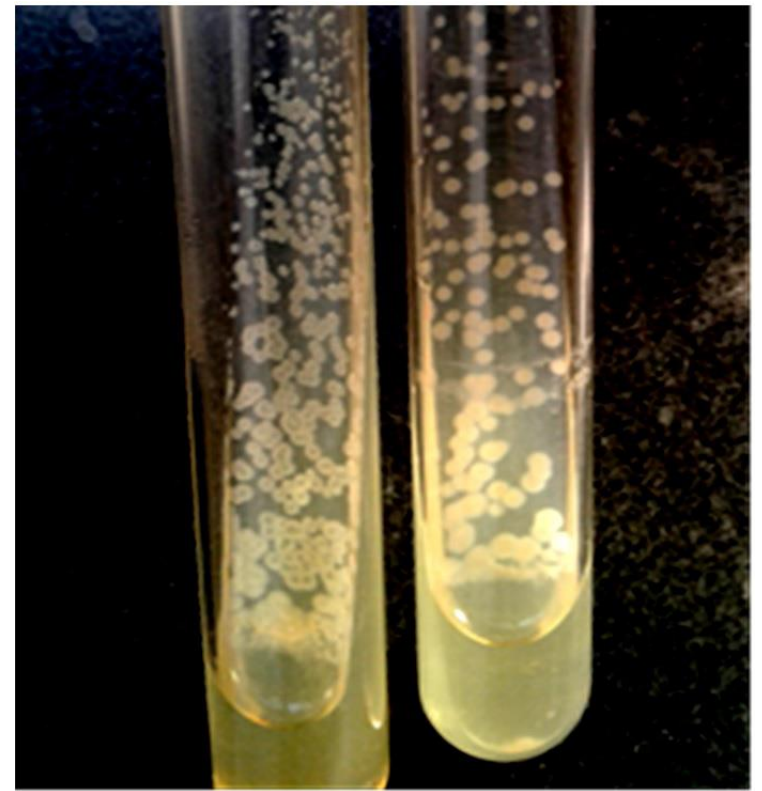

Fig. 1. The small, smooth, and grey colonies of B. mallei on nutrient agar after $48 \mathrm{~h}$ incubation at $37^{\circ} \mathrm{C}$.

ducibility of PFGE was checked twice by preparing agarose-embedded DNA from 5 isolates of $B$. mallei (Fig. 6). Similarity coefficients between two replicates ranged between 93.5 and $95.2 \%$ (mean \pm standard deviation, $94.23 \% \pm 1.29 \%$ ). The PFGE types were characterized based on DNA banding patterns. According to both enzymatic digestion patterns by using AflII and VspI, we found three different clonal types or clusters, including PFGE type of $B$. mallei Razi 325 strain (Clone I), PFGE type of Tiger, Kordan, and Oshnavieh strains (Clone II), and PFGE type of Semirom strain (Clone III). B. mallei Razi 325 was categorized as an unrelated strain which was belonged to different cluster differing by more than four bands. Tiger, Kordan, and Oshnavieh strains were regarded as genotypically indistinguishable being identical patterns. Interestingly, Semirom strain indicated a single band differentiation in digestion patterns of both AflII and VspI for PFGE typing, and considered as a related strain.

Histopathological findings. The swollen scrotum, edematous, and orchitis were observed in the guinea pig after $72 \mathrm{~h}$ IP injection. The guinea pig was euthanized with chloroform, dissected with the routine techniques, and testicle tissue was immersed in formaldehyde (Fig. 7). The histological evaluations exhibited tubular hyperemia, infiltration of the epididymis, and pyogranulomatous inflammation re- 


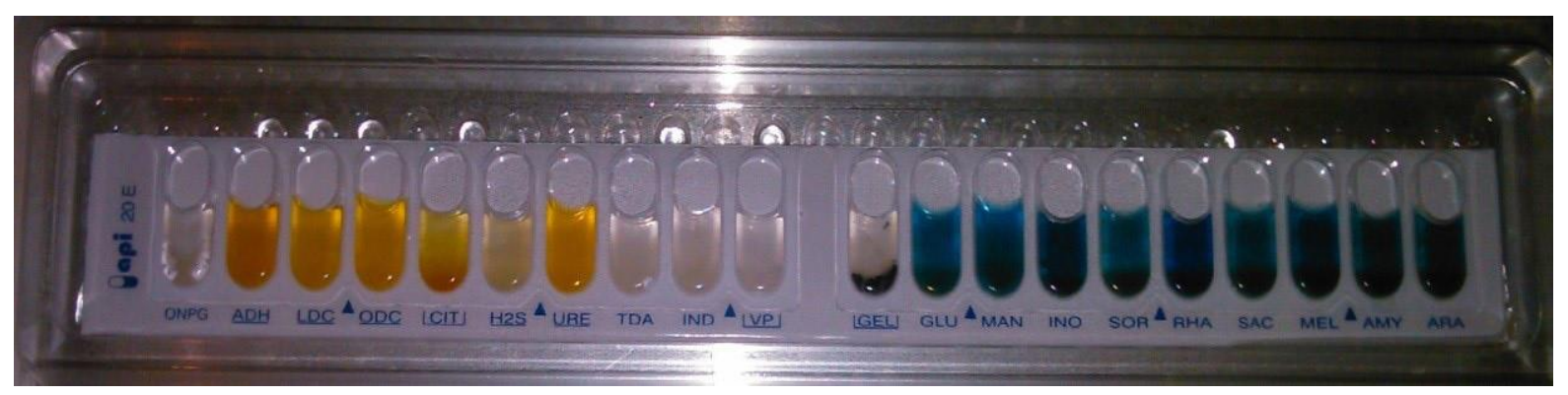

Fig. 2. API 20NE identification system and biochemical characterization of B. mallei isolates

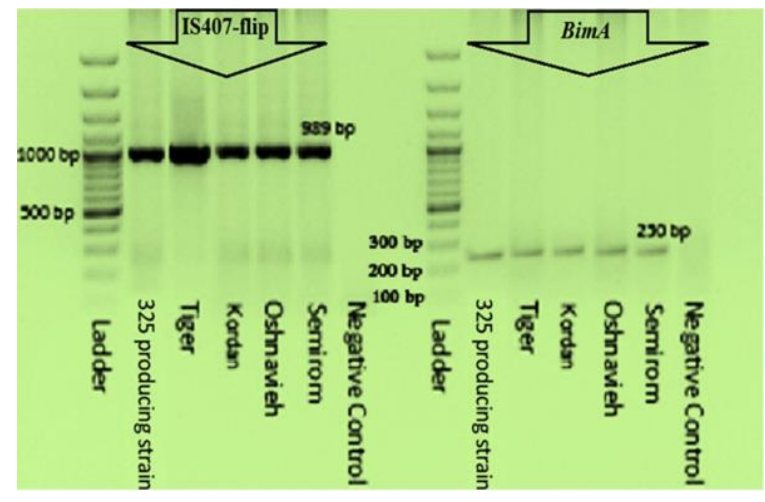

Fig. 3. PCR amplification of IS407-flip ( 989 bp) and BimA (250 bp) genes of B. mallei strains.

action in the parenchyma and scrotal areas (Fig. 8). Polymorphonuclear (PMN) leukocytes infiltration was also seen in the testicle tissue which was inconsistently progressed into discrete pyogranulomas.

\section{DISCUSSION}

In the current paper, we applied PFGE as a more easily understood and accessible method for high-resolution typing of B. mallei isolates. Glanders, the OIE notifiable disease, is recognized as a priority disease for governments in the affected areas considering the zoonotic potential, lack of vaccine availability, easy transmission, and its implications for vulnerability among different populations of the solipeds. The reported cases of $B$. mallei in animals and other accidental hosts such as human are still rare in Iran. However, the implementation of government-sponsored programs is considered a legal obligation for controlling the disease and reducing its losses due to the importance of the B. mallei, as a deadly biological pathogen, from the perspective of the Convention on the Prohibition of the Development, Production,

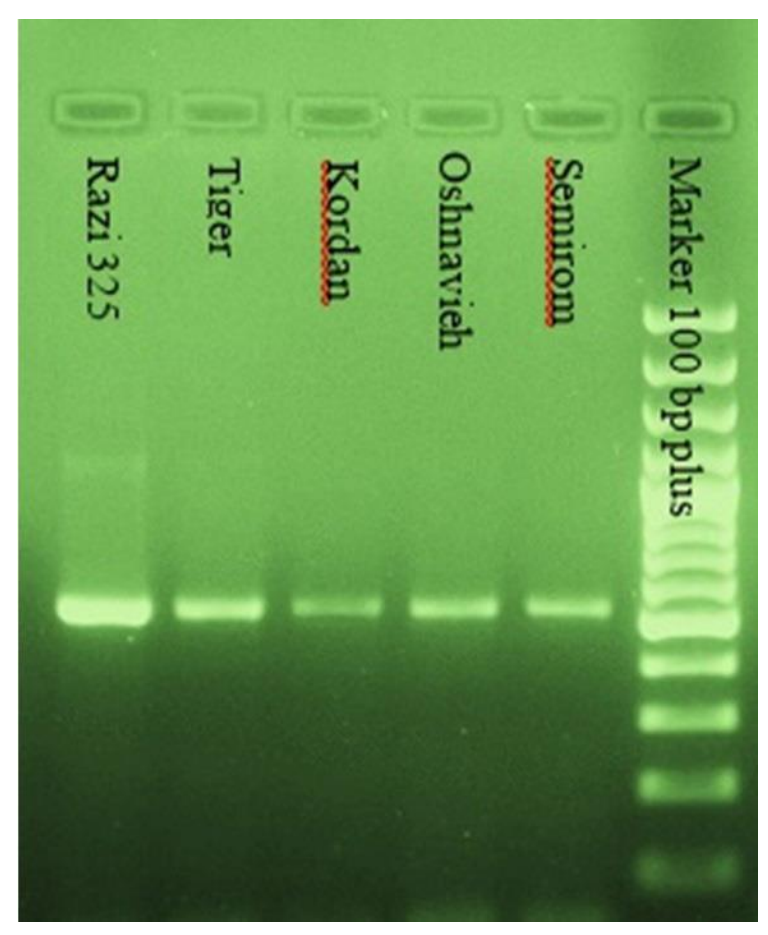

Fig. 4. PCR amplification of 23 rRNA of B. mallei isolates (526 bp)

and Stockpiling of Bacteriological (Biological) and Toxin Weapons and on their Destruction (known as the Biological and Toxin Weapons Convention, or BTWC).

Our pathological findings showed that the main gross lesion was orchitis which was observed in the guinea pig after $72 \mathrm{~h}$ IP injection of the standard strain of $B$. mallei Razi 325. The main histopathological lesions were pyogranulomatous inflammatory cell infiltrate in the testicular tissue. Currently, not enough data exist on histopathological changes of $B$. mallei in the guinea pig as a susceptible animal model.

Several methods have been used to establish relatedness between Burkholderia isolates, including biotyping, serotyping, phenotyping, and genotyping, es- 

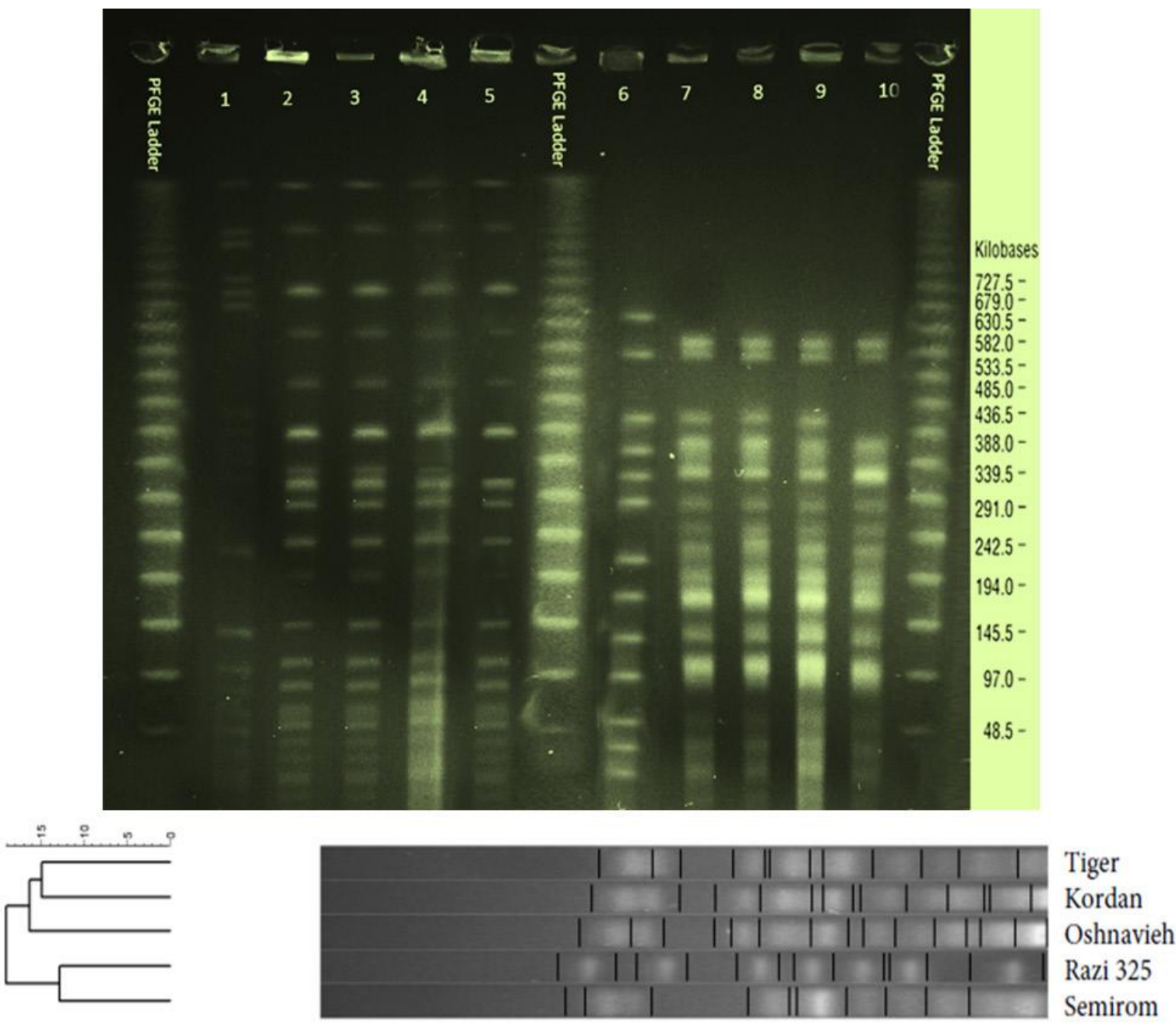

Fig. 5. PFGE algorithm for $B$. mallei strains typing. PFGE-standard lambda ( $\lambda$ ) ladder (Promega, USA) in the lateral and central lanes of the gel: $48.5-1,000 \mathrm{~kb}$ in $48.5 \mathrm{~kb}$ increments ( $\lambda$ cl857Sam7 concatemers); Lanes 1-5: restriction profile by AflII, Lanes 6-10: restriction profile by VspI. Lanes 1,6: B. mallei Razi 325 strain (Clone I); Lanes 2,7: B. mallei Tiger strain (Clone II); Lanes 3,8: B. mallei Kordan strain (Clone II); Lanes 4,9: B. mallei Oshnavieh strain (Clone II); Lanes 5,10: B. mallei Semirom strain (Clone III)

pecially PCR-based fingerprinting techniques. OIE is developing reliable diagnostic protocols for glanders, suggesting PCR-based molecular technique which has been progressed in many OIE-supervised reference laboratories. PCR-based methodologies have been used to detect and differentiate the $B$. pseudomallei complex (B. pseudomallei, B. mallei, and B. thailandensis) as previously described by Lowe et al. (12). The other approaches such as multiplex PCR(13), loop-mediated isothermal amplification (LAMP) assay (14), and TaqMan qPCR/RT-qPCR assay by targeting an SNP in some virulence genes (15) with high accuracy were developed to detect $B$. mallei in recent studies.
PCR study targeting the Burkholderia intracellular motility A (BimA) gene and the flagella biosynthesis protein insertion element (IS407-flip) has been reported to detect B. malle $i$ with an accuracy of $100 \%$ $(10,16)$. BimA is responsible for actin-based motility and cell-to-cell spread of B. mallei (16). BimA is also present in $B$. pseudomallei, although the terminal $300 \mathrm{bp}$ of the gene is over $99 \%$ similar to the 3 '-end of B. mallei BimA, its 5'-end displayed no nucleotide sequence similarities to the same region of $\operatorname{Bim} A(17)$. The insertion element, IS407, has a potential role in the genetic rearrangement of $B$. mallei. The genetic difference of fliP (flagellin P) between B. pseudomal$l e i$ and $B$. malle $i$ is used to design specific primers for 


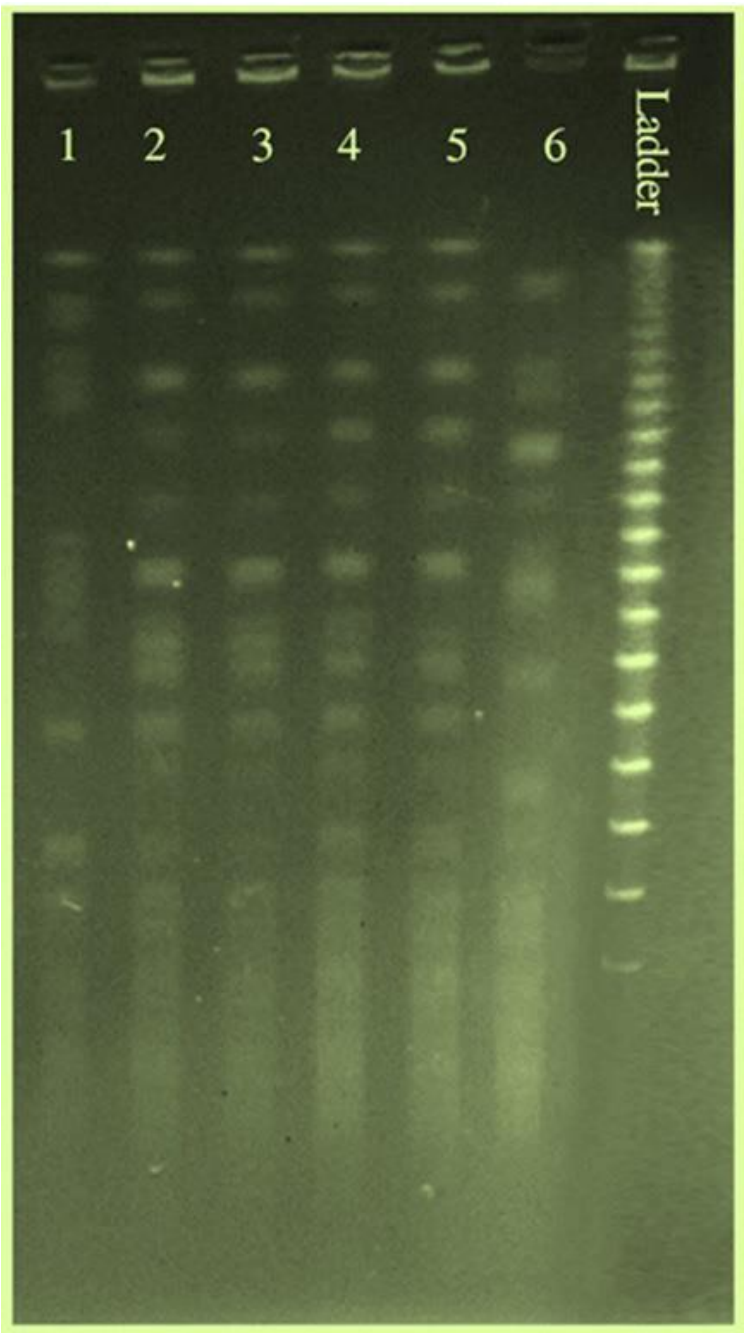

Fig. 6. The reproducibility power test of PFGE. The Af1II-digested genomic DNA patterns of B. mallei and $B$. pseudomallei. Lanes 1: B. mallei Razi 325 strain; Lanes 2: B. mallei Tiger strain; Lanes 3: B. mallei Kordan strain; Lanes 4: B. mallei Oshnavieh strain; Lanes 5: B. mallei Semirom strain; Lane 6: B. pseudomallei (Razi Type Culture Collection (RTCC)).

the detection of B. mallei by PCR (10).

There is little information about the epidemiology and genetic relatedness of $B$. mallei in Iran. PFGE is generally considered the "gold standard" in the molecular typing of microorganisms. Nevertheless, there are only a few studies that have applied PFGE in assessing B. mallei epidemiology (18). The genomic approaches using multi-locus sequence typing (MLST) and array-based comparative genomic hybridization $(\mathrm{aCGH})$ clusters have earlier been applied for phylogenetic studies and the relationship of B. mallei strains (19). The establishment of interna-

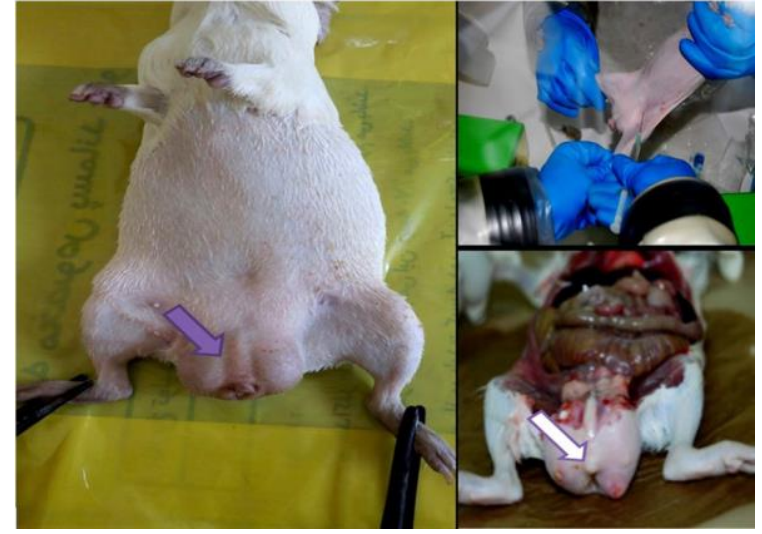

Fig. 7. The Strauss phenomenon and testicle swelling of guinea pig following the intraperitoneal (IP) injection of Burkholderia mallei

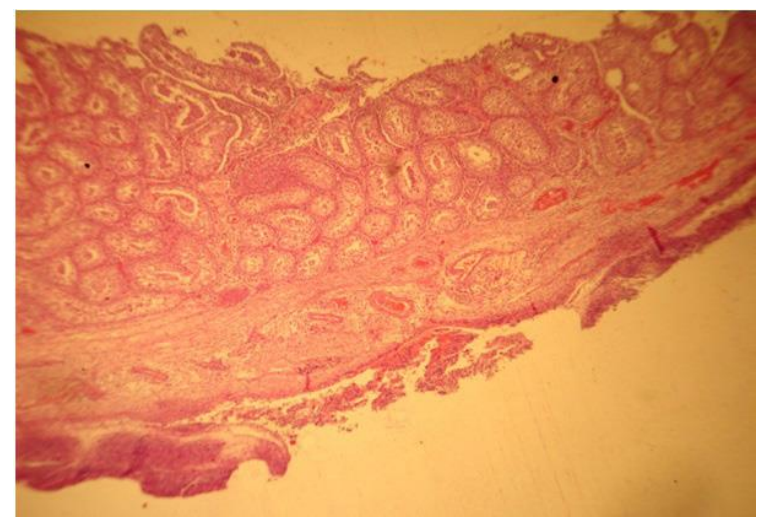

Fig. 8. The cross section of testicle tissue of male guinea pig $72 \mathrm{~h}$ after intraperitoneal (IP) injection of B. mallei (Hematoxylin and Eosin, H\&E, staining $\times 40$ ): The tubular hyperemia, infiltration of the epididymis, and pyogranulomatous inflammation reaction in the parenchyma and scrotal areas.

tional outbreak detection networks and standardization of the approaches for pathogen phylogeny and population studies have been provided by contemporary typing methods such as PFGE and MLST (20). PFGE includes surrounding organism in agarose, in situ lysing organism, and digesting genomic DNA with restriction endonucleases. Genomic DNA fragments embedded in agarose plugs are inserted into gel wells, resolved into the pattern of separate bands on agarose gel, then compared with one another to determine their relatedness.

The PFGE types were defined according to the band pattern similarities. The closely related isolates were detected based on one to three band differences, while identical isolates showed no band differences. 
PFGE typing of B. pseudomallei by using the restriction endonucleases $\mathrm{XbaI}$ and SpeI has previously been described $(21,22)$. A study showed that the discriminatory power of SpeI was higher than the XbaI for PFGE typing of clinical B. pseudomallei isolates (22). This finding may be generalized for PFGE typing of $B$. mallei since B. mallei is believed to have originated from $B$. pseudomallei. However, it seems that $B$. mallei contains numerous IS elements resulting in multiple deletions and rearrangements of the genome relative to $B$. pseudomallei (23). A good resolution by PFGE using SpeI together with clustering of some geographically related $B$. mallei isolates was demonstrated by Chantratita et al. (24). Selecting suitable restriction enzymes is significant to distinguish B. mallei strains with high resolution in PFGE. We successfully applied AflII and VspI with high resolving power in PFGE typing of $B$. mallei within the shortest running time $(18 \mathrm{~h})$ showing three different clone types of $B$. mallei isolates. The reproducibility of both enzymes was also checked and deduced the same remarkable results. This is the first report on PFGE analysis of $B$. mallei by the newly established enzymes $A f l \mathrm{II}$ and $V s p \mathrm{I}$.

In conclusion, we suggest that PFGE is feasible for reference laboratories that will be confronted primarily with outbreaks of glanders. Developing a database for PFGE banding pattern analysis of B. malle $i$ may be a valuable resource in the future outbreak of animal or human disease.

\section{ACKNOWLEDGEMENTS}

This study was financially supported by the Razi Vaccine and Serum Research Institute, Karaj, Iran under project grant No. 2-18-18-94115.

\section{REFERENCES}

1. Nguyen HN, Smith ME, Hayoun MA (2021). Glanders and melioidosis. In: StatPearls [Internet]. Treasure Island (FL): StatPearls Publishing.

2. Khan I, Wieler LH, Melzer F, Elschner MC, Muhammad G, Ali S, et al. Glanders in animals: a review on epidemiology, clinical presentation, diagnosis and countermeasures. Transbound Emerg Dis 2013;60:204221.

3. Van Zandt KE, Greer MT, Gelhaus HC. Glanders: an overview of infection in humans. Orphanet J Rare Dis 2013:8:131.

4. Inglis TJJ, Merritt AJ (2015). Burkholderia pseudomallei and Burkholderia mallei. In: Molecular Medical Microbiology. Ed(s), YW Tang, M Sussman, D Liu, I Poxton, J Schwartzman. Academic Press, 2nd ed. Crawley, WA, Australia, pp. 769-791.

5. Schutzer SE, Schlater LR, Ronning CM, DeShazer D, Luft BJ, Dunn JJ, et al. Characterization of clinically-attenuated Burkholderia mallei by whole genome sequencing: candidate strain for exclusion from select agent lists. PLoS One 2008;3(4):e2058.

6. Yazdansetad S, Mosavari N, Tadayon K, Mehregan I. Development of an immunoblotting assay for serodiagnosis of Burkholderia mallei infection: the wholecell proteome-based paradigm. Iran J Microbiol 2019;11:232-238.

7. Khaki P, Mosavari N, Khajeh NS, Emam M, Ahouran M, Hashemi S, et al. Glanders outbreak at Tehran zoo, Iran. Iran J Microbiol 2012;4:3-7.

8. OIE World Organization for Animal Health [OIE]. Manual of Diagnostic Tests and Vaccines for Terrestrial Animals 2019.

9. Ulrich RL, Ulrich MP, Schell MA, Kim HS, DeShazer D. Development of a polymerase chain reaction assay for the specific identification of Burkholderia mallei and differentiation from Burkholderia pseudomallei and other closely related Burkholderiaceae. Diagn Microbiol Infect Dis 2006;55:37-45.

10. Scholz HC, Joseph M, Tomaso H, Al Dahouk S, Witte A, Kinne J, et al. Detection of the reemerging agent Burkholderia mallei in a recent outbreak of glanders in the United Arab Emirates by a newly developed fliP-based polymerase chain reaction assay. Diagn Microbiol Infect Dis 2006;54:241-247.

11. Bauernfeind A, Roller C, Meyer D, Jungwirth R, Schneider I. Molecular procedure for rapid detection of Burkholderia mallei and Burkholderia pseudomallei. J Clin Microbiol 1998;36:2737-2741.

12. Lowe W, March JK, Bunnell AJ, O'Neill KL, Robison RA. PCR-based methodologies used to detect and differentiate the Burkholderia pseudomallei complex: B. pseudomallei, B. mallei, and B. thailandensis. Curr Issues Mol Biol 2014;16:23-54.

13. Lee MA, Wang D, Yap EH. Detection and differentiation of Burkholderia pseudomallei, Burkholderia mallei and Burkholderia thailandensis by multiplex PCR. FEMS Immunol Med Microbiol 2005;43:413-417.

14. Mirzai S, Safi S, Mossavari N, Afshar D, Bolourchian M. Development of a loop-mediated isothermal amplification assay for rapid detection of Burkholderia mallei. Cell Mol Biol (Noisy-le-grand) 2016;62:32-36.

15. Lowe CW, Satterfield BA, Nelson DB, Thiriot JD, Heder MJ, March JK, et al. A quadruplex real-time PCR 
assay for the rapid detection and differentiation of the most relevant members of the $B$. pseudomallei complex: B. mallei, B. pseudomallei, and B. thailandensis. PLoS One 2016;11(10):e0164006.

16. Stevens JM, Ulrich RL, Taylor LA, Wood MW, Deshazer D, Stevens MP, et al. Actin-binding proteins from Burkholderia mallei and Burkholderia thailandensis can functionally compensate for the actin-based motility defect of a Burkholderia pseudomallei bimA mutant. J Bacteriol 2005;187:7857-7862.

17. Stevens MP, Stevens JM, Jeng RL, Taylor LA, Wood MW, Hawes P, et al. Identification of a bacterial factor required for actin-based motility of Burkholderia pseudomallei. Mol Microbiol 2005;56:40-53.

18. Jakupciak JP, Wells JM, Karalus RJ, Pawlowski DR, Lin JS, Feldman AB. Population-sequencing as a biomarker of Burkholderia mallei and Burkholderia pseudomallei evolution through microbial forensic analysis. J Nucleic Acids 2013;2013:801505.

19. Godoy D, Randle G, Simpson AJ, Aanensen DM, Pitt TL, Kinoshita R, et al. Multilocus sequence typing and evolutionary relationships among the causative agents of melioidosis and glanders, Burkholderia pseudomallei and Burkholderia mallei. J Clin Microbiol
2003:41:2068-2079.

20. Gilmour MW, Graham M, Reimer A, Van Domselaar G. Public health genomics and the new molecular epidemiology of bacterial pathogens. Public Health Genomics 2013;16:25-30.

21. Ko WC, Cheung BM, Tang HJ, Shih HI, Lau YJ, Wang LR, et al. Melioidosis outbreak after typhoon, southern Taiwan. Emerg Infect Dis 2007;13:896-898.

22. Chua KH, See KH, Thong KL, Puthucheary SD. SpeI restriction enzyme displays greater discriminatory power than XbaI enzyme does in a pulsed-field gel electrophoresis study on 146 clinical Burkholderia pseudomallei isolates. Jpn J Infect Dis 2011;64:228233.

23. Majerczyk CD, Brittnacher MJ, Jacobs MA, Armour CD, Radey MC, Bunt R, et al. Cross-species comparison of the Burkholderia pseudomallei, Burkholderia thailandensis, and Burkholderia mallei quorum-sensing regulons. J Bacteriol 2014;196:3862-3871.

24. Chantratita N, Vesaratchavest M, Wuthiekanun V, Tiyawisutsri R, Ulziitogtokh T, Akcay E, et al. Pulsedfield gel electrophoresis as a discriminatory typing technique for the biothreat agent Burkholderia mallei. Am J Trop Med Hyg 2006;74:345-347. 